Aggregation of DNA by analogs of spermidine; enzymatic and structural studies

Kalkunte S.Srivenugopal, David E.Wemmer*,1 and David R.Morris $\S$

Departments of Biochemistry and ${ }^{1}$ Chemistry, University of Washington, Seattle, WA 98195, USA

Received November 26, 1986; Revised and Accepted February 23, 1987

ABSTRACT: A homologous series of spermidine analogs, with defined abilities to replace the natural polyamine in supporting cell growth, was examined for its influence on the structure of supercoiled, aggregated DNA and on the ability of the DNA aggregates to act as substrates for various enzymes. The concentration of amine necessary to aggregate negatively supercoiled $\mathrm{Col}_{1}$ DNA was progressively increased as the diaminobutane moiety of spermidine was extended beyond 5 methylene groups. $1 \mathrm{H}$ and 31P-NMR spectroscopy suggested that less rigid DNA aggregates were formed by spermidine analogs than by spermidine itself. Spermidine and its analogs differentially modulated the activities of bacterial and mammalian type I topoisomerases and EcoRI restriction endonuclease on aggregated DNA in a manner reminiscent of the abilities of the amines to stimulate cell growth. When DNA was not aggregated, the influence of the various amines on these reactions was almost identical. These results are discussed in relation to the structures of the DNA aggregates in the presence of the various triamines.

\title{
INTRODUCTION:
}

Polyamines such as spermidine are natural polycations ubiquitously present in all living cells at millimolar intracellular concentrations $(1,2)$. Evidence accrued over the years strongly supports the concept that adequate levels of polyamines are necessary for cell proliferation and growth (3-6). Interaction of these cationic ligands with DNA and RNA is likely to be important in modulating the structure and function of nucleic acids $(6,7)$. Evaluation of the biological significance of polyamine interactions in vitro has been difficult. Spermidine and other polyamines, being highly charged cations, exhibit non-specific ionic interactions which may be unrelated to possible specific intracellular functions.

As an attempt to assess this situation, a homologous series of spermidine analogs of the structure $\mathrm{NH}_{2}\left(\mathrm{CH}_{2}\right)_{3} \mathrm{NH}\left(\mathrm{CH}_{2}\right)_{x} \mathrm{NH}_{2}$ where $x$ is an integer from 5 to 8 [ $x=4$ for spermidine] was earlier synthesized in this laboratory (8). These analogs are designated $\mathrm{AP}_{5}$ to $\mathrm{AP}_{8}$ throughout this paper. Using $\underline{\mathrm{E}}$. coli strains auxotrophic for spermidine, we then studied the restoration of growth and DNA replication by providing spermidine or its analogs at equal intracellular levels $(8,9)$. As extra methylene groups were added to the spermidine molecule, the growth rate and DNA chain elongation rate both decreased relative to that of spermidine-supplemented cells; AP7 and AP8 were devoid of activity in stimulating either parameter. Similar specificity has been found with animal cells depleted of spermidine by biosynthetic inhibitors (10). In view of these findings, identification of in vitro interactions of spermidine that show the same specificity with the analogs as observed in vivo would clearly have biologically relevance (11). The enzymatic and NMR studies reported here, as well as other physiochemical investigations (12-14), point 
to the structural importance of the spermidine molecule in its binding to DNA and suggest limitations in the counterion condensation theory (15) in explaining these interactions.

\section{EXPERIMENTAL PROCEDURES:}

Chemicals. Spermidine analogs of the general structure $\mathrm{NH}_{2}\left(\mathrm{CH}_{2}\right)_{3} \mathrm{NH}\left(\mathrm{CH}_{2}\right)_{x} \mathrm{NH}_{2}(\mathrm{x}$ is 4 for spermidine and varies from 5 to 8 for analogs) were synthesized as their hydrochloride salts (8). The analogs were checked for purity by thin layer chromatography and are designated as follows: $\mathrm{N}$-(3aminopropyl)-1,5-diaminopentane, AP5; N-(3-aminopropyl)-1,6-diaminohexane, AP6; $\mathrm{N}$-(3-aminopropyl)1,7-diaminoheptane, AP7; $\mathrm{N}$-(3-aminopropyl)-1,8-diaminooctane, AP8. Stock solutions of spermidine.3 $\mathrm{HCl}$ (Calbiochem) and its analogs were neutralized to $\mathrm{pH}$ 7.0. The other products used were: nitrocellulose (Schleicher and Schuell), agarose (Bethesda Research Laboratories), calf thymus DNA (Sigma) and hexaminecobalt (Aldrich). Isolation of Col $E_{1}$ plasmid DNA in its supercoiled form and preparation of $[3 \mathrm{H}] \mathrm{Col} \mathrm{E}_{1}$ DNA have been described (16).

Enzymes. Calf thymus type I DNA topoisomerase was purchased from Bethesda Research Laboratories. E. coli topoisomerase I was purified as earlier (16). A gift sample of this enzyme from Dr. Robert Low was also used in some experiments. E. coli DNA gyrase was purified using a novobiocin Sepharose column and also reconstituted from gyr $A$ and gyr B subunits obtained from Dr. Martin Gellert. Nuclease $S_{1}$ and restriction enzymes Smal, Pstl, EcoRI were procured from Bethesda Research Laboratories. Mung bean nuclease was purchased from P. L. Biochemicals.

DNA Aggregation Assay. The microcentrifuge assay described by Krasnow and Cozzarelli (17) was used to monitor DNA aggregation in reaction mixtures employed for enzyme assays in this study. Enzyme assays were set up in duplicate; at the end of incubation, one sample was treated with sarkosylEDTA for electrophoresis. The other sample was sedimented in a Beckman microfuge for 10 min without adding stop mix. To detect unsedimented DNA, the supernatant after centrifugation was either quantitated by liquid scintillation (if [ $3 \mathrm{H}] \mathrm{Col} \mathrm{E}_{1}$ DNA was used) or subjected to gel electrophoresis followed by ethidium bromide staining when DNA substrates were unlabeled.

Enzyme Assays. The levels of monovalent and divalent cations in the reaction mixtures were varied in combination with polyamines to induce aggregation or disaggregation of DNA. The reaction components were in a total volume of 20-30 $\mu \mathrm{l}$ with $1 \mu \mathrm{g}$ of native Col $E_{1}$ DNA per assay; enzymes were added last and incubated at $370 \mathrm{C}$. The reactions were terminated by addition of a sarkosyl-EDTA solution and analyzed in $1.3 \%$ agarose gels. Details of gel electrophoresis, ethidium bromide staining and photography have been described (16), or are provided in the figure legends.

Analysis of DNA Linearized by $\mathbf{S}_{1}$ Nuclease. The volume of the assay mixture described in the legend of Figure 4 was increased 125-fold and made $5 \mathrm{mM}$ in spermidine to aggregate Col $E_{1}$ DNA. $\mathrm{S}_{1}$ nuclease (1000 units) was added and the reaction incubated for $3 \mathrm{~h}$ at $370 \mathrm{C}$ to ensure maximum production of the 3.3-kb fragments. This linear DNA ran as a distinct band, well separated from the supercoiled intact molecule. It was excised after staining with ethidium bromide and the agarose was melted at $650 \mathrm{C}$. DNA was phenol-extracted into the aqueous phase and purified on an Elutip-d column (Schleicher and Schuell) followed by ethanol precipitation. 


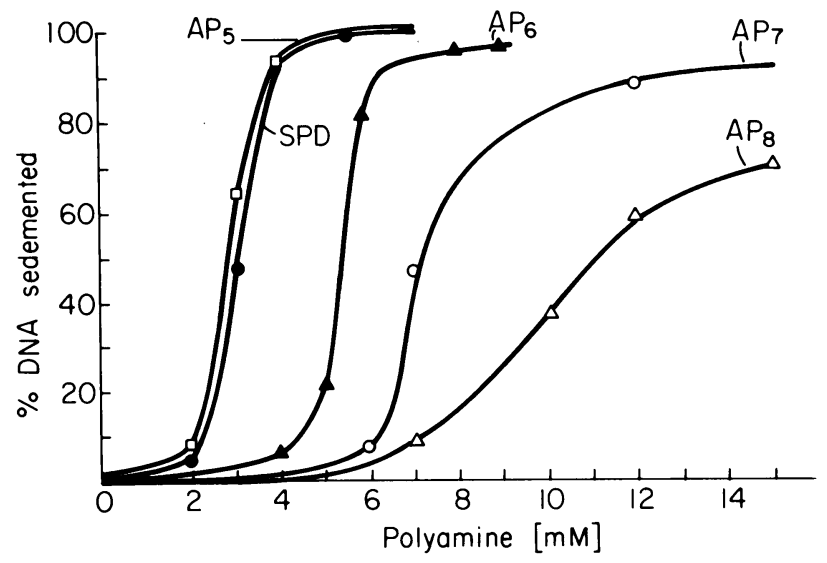

Figure 1: Aggregation of Col E1 supercoiled DNA by spermidine and its analogs. Aggregation of native $[3 \mathrm{H}] \mathrm{Col} \mathrm{E}_{1} \mathrm{DNA}(1 \mu \mathrm{g}, 50,000 \mathrm{cpm})$ was determined by the microcentrifuge assay (see Experimental Procedures) in a solution containing $20 \mathrm{mM}$ Tris- $\mathrm{HCl}(\mathrm{pH} 7.5), 5 \%$ glycerol, $3 \mathrm{mM} \mathrm{MgC} / 2$ and $5 \mathrm{mM} \mathrm{KCl}$. Note that conditions employed in the aggregation assay are similar to the reaction components used for assaying E. coli topisomerase I shown in Figures 7 and 8 . The results presented are an average of duplicate samples. SPD $=$ spermidine.

In Vitro Assay for Phage Lambda Integrative Recombination. DNA substrates and the proteins required for these experiments were kindly provided by Dr. Howard Nash and the studies were performed in his laboratory at the National Institutes of Health, Bethesda. The assay details have been published (18). The influence of spermidine and its analogs were tested in reactions containing $50 \mathrm{mM}$ Tris- $\mathrm{HCl}$ (pH 7.8), $70 \mathrm{mM} \mathrm{KCl}, 1 \mathrm{mM}$ EDTA, $0.25 \mu \mathrm{g}$ each of supertwisted pPA1 DNA (with attP site) and linear pBB105 DNA with attB site, $80 \mathrm{ng}$ integrase (int protein) and 5 units of integration host factor (IHF). The recombinant product was analyzed by agarose gel electrophoresis.

Miscellaneous Procedures. Nick translation of Col $E_{1}$ DNA and its EcoRI-Smal fragment, transfer of DNA from agarose gels to nitrocellulose and hybridization to DNA probes were performed by standard procedures (19). Rehybridization of blots was according to Thomas (20). Methods followed for NMR experiments are described in the figure legends.

\section{RESULTS:}

Aggregation of Col $E_{1}$ DNA. Separation of sedimented DNA from the free form by centrifugation is a simple and convenient method to monitor DNA aggregation $(17,21)$. We used this procedure to study aggregation of Col $E_{1}$ DNA by spermidine and its analogs in the presence of $3 \mathrm{mM}$ $\mathrm{Mg}^{2+}$ and $5 \mathrm{mM} \mathrm{KCl}$. As illustrated in Figure 1, spermidine and its nearest analog, AP5 were most effective, showing the cooperative transition expected for this phenomenon (22). The concentration of spermidine analogs required to initiate DNA aggregation was dependent on the length of the methylene chain under these conditions; the longer chain analogs $\mathrm{AP} 7$ and $\mathrm{AP} 8$ clearly required higher 

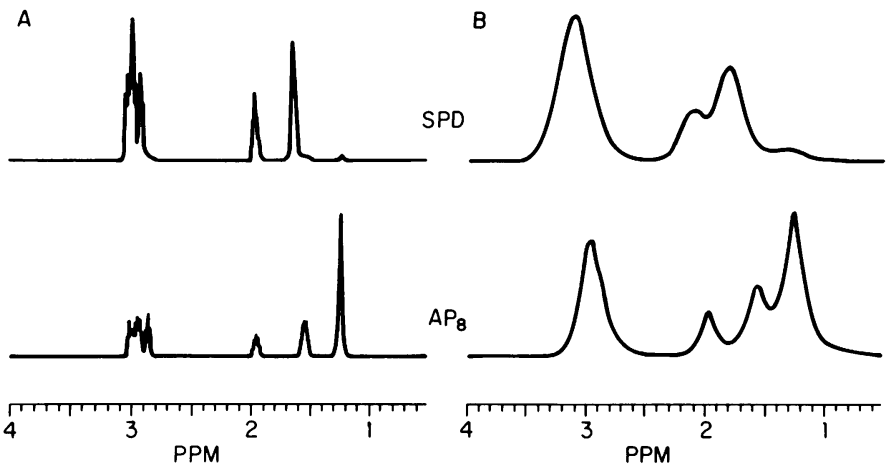

Figure 2: $500 \mathrm{MHz}$ proton NMR spectra of the free and bound polyamines in condensed calf thymus DNA. A sample of condensed DNA for this experiment was prepared by the following procedure: $20 \mathrm{mg}$ of calf thymus DNA (highly polymerized type from Sigma) and polyamine hydrochlorides were dissolved in $\mathrm{D}_{2} \mathrm{O}$ (99.9\% Aldrich) after lyophilizing to dryness in the same solvent. DNA solution (2 $\mathrm{mg} / \mathrm{ml}$ ) was placed in 1- $\mathrm{ml}$ aliquots in siliconized microfuge tubes and a concentrated solution of spermidine or AP8 $(0.4 \mathrm{M})$ was added to form a fibrous precipitate of DNA. The mixtures were vortexed and allowed to stand at room temperature for $20 \mathrm{~min}$. The tubes were briefly microfuged. DNA pellets prepared in this way adhere to the tip of a narrow stirring rod. The pellets were combined into new tubes and washed three times by suspending in fresh $\mathrm{D}_{2} \mathrm{O}$ and centrifuging to remove accessible polyamines. DNA precipitates were then transferred to an NMR tube and covered with $\mathrm{D}_{2} \mathrm{O}$. NMR spectra were obtained on a Bruker WM500 Spectrometer at $260 \mathrm{C}$. Panel A - proton spectra of free polyamines. Panel B - proton spectra of spermidine and AP8 bound in the calf thymus DNA complexes. No leaching of polyamines form the condensed DNA was detected during the experimental period. The correlation time for the tumbling of polyamine protons was calculated using the linewidth data from the spectra in Panel B.

concentrations for complete aggregation. The behavior of these triamines followed a similar trend when DNA aggregation in buffers of low and moderate ionic strength was assayed by agarose gel electophoresis (details in Experimental Procedures; data not shown). The reported level of spermidine $(5 \mathrm{mM})$ required to aggregate DNA is similar to that observed earlier under comparable conditions (17).

NMR Studies. Polyamine-induced condensation of DNA is a valuable model for DNA packing in viruses and chromatin studies (7). No information is available to date on the molecular dynamics of components in condensed DNA. This consideration may be important, since aggregation of DNA appears to be an important factor in the modulation of the activities of some enzymes by polyamines, as will be shown in this paper.

DNA preparations condensed by spermidine or other polyamines contain bound molecules of these cations in the complex. The molar ratio of DNA phosphorus to polyamines is approximately $5: 1$ (23). We used [ ${ }^{14} \mathrm{C}$ ]spermidine to condense calf thymus DNA and found that leaching of bound spermidine into the medium was insignificant $[<0.1 \%]$ at $250 \mathrm{C}$ during $3 \mathrm{~h}$ of incubation (data not shown). Taking advantage of this stability, we used DNA condensates to analyze the bound polyamine protons by NMR. In the $500 \mathrm{MHz}$ proton spectra represented in Figure 2, calf thymus DNA resonances are not detectable because of its high molecular weight (24). The NMR spectrum of spermidine or AP8 alone 


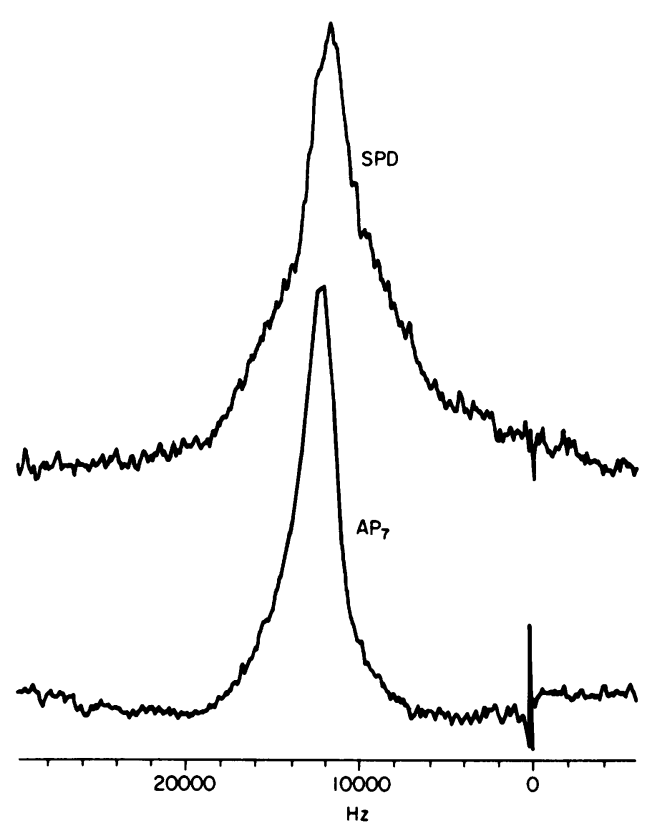

Figure 3: $109 \mathrm{MHz}^{31} \mathrm{P}$ Spectra of calf thymus DNA condensed by spermidine or AP7. Condensed DNA was prepared by the procedure described in Legend to Figure 2 (using $\mathrm{H}_{2} \mathrm{O}$ instead of $\mathrm{D}_{2} \mathrm{O}$ ). The DNA pellets were loosely packed into 7-mm rotors which were sealed with a plastic cap. Spectra were taken with a homebuilt spectrometer (270 MHz $1 \mathrm{H}$ frequency) using a magic angle probe (all spectra were taken without sample spinning). Data were collected with $1 \mathrm{H}$ decoupling (during acquisition only) using 900 pulses, a recycle time of $3 \mathrm{sec}$, spectral width of $36 \mathrm{MHz}, 2048$ data points and at a sample temperature of $22.50 \mathrm{C}$. Three thousand scans were averaged per spectrum. Zero frequency in the spectrum represents the spectrometer's operating frequency; no referencing of the spectrum was done.

contains narrow resonance lines typical of small molecules. The broad polyamine spectra in the complexes point to the reduced mobility of these cations in association with DNA relative to the free polyamines in solution. However the mobility of the polyamines is clearly independent of the DNA, since the DNA protons are invisible in these experiments. Of particular interest are the narrower linewidths of $\mathrm{AP}_{8}$ in the DNA complex relative to that of spermidine. Linewidth calculations have been carried out to estimate the rotational correlation time of spermidine and AP8 protons in condensed DNA. The calculations are based on the simplest form of relaxation theory, assuming an isotropic tumbling of a proton with a single correlation time and all relaxation from the geminal proton (25). The correlation times obtained were $4.2 \times 10^{-8} \mathrm{sec}$ for the tumbling of spermidine and $2.9 \times 10^{-8} \mathrm{sec}$ for AP8 protons. The broad polyamine resonances changed to narrow spectra, characteristic of free polyamines when the DNA pellets were dissolved in $\mathrm{D}_{2} \mathrm{O}$ containing $1 \mathrm{M} \mathrm{NaCl}$ (data not shown).

31P NMR spectroscopy in solids is useful for the study of internal motions in DNA samples (2628). Spectra of calf thymus DNA aggregates with spermidine and AP7 are shown in Figure 3 . These 


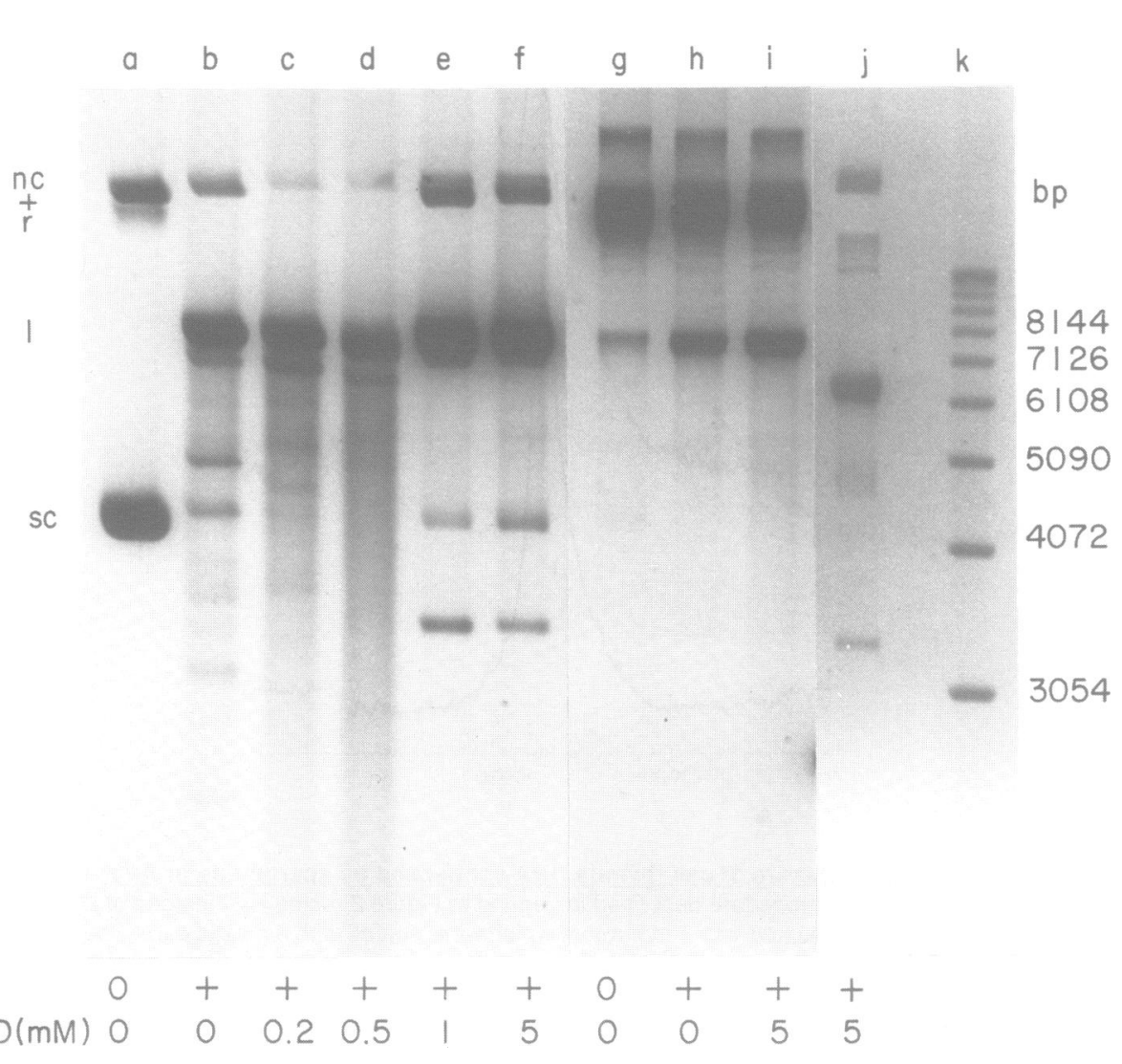

Figure 4: Induction of a specific cleavage by $S_{1}$ nuclease in Col $E_{1}$ DNA: dependence on DNA aggregation and topology. Negatively supercoiled Col $E_{1}$ DNA (a to $f$ and $j$ ) or its relaxed form ( $g$ to $\left.i\right)$ were incubated with 100 units of $S_{1}$ nuclease for $40 \mathrm{~min}$ at $370 \mathrm{C}$ in the presence of $20 \mathrm{mM}$ sodium acetate (pH 6.8), $7 \%$ glycerol, $1.0 \mathrm{mM}$ zinc acetate, and $20 \mathrm{mM} \mathrm{NaCl}$. Spermidine concentration was varied in reactions $\mathrm{c}$ through $\mathrm{f}$ as indicated. The electrophoretic patterns shown in lanes $j$ and $k$ are from a separate experiment. Lane $\mathrm{j}$ represents the cleavage of supercoiled $\mathrm{Col}_{1} \mathrm{DNA}$ in the aggregated state (similar to lane i). DNA markers are shown in lane $k$. $(n c=$ nicked circular, $r=$ relaxed, $s c=$ supercoiled and $\mathrm{I}=$ linear forms)

aggregates show 31P spectra similar to those seen with a moderately hydrated DNA powder (28). The aggregate formed with AP7 displays a narrower linewidth than that with spermidine, suggesting more freedom of internal motion of the DNA chains in the complexes with the analog.

These NMR studies clearly revealed differences between the DNA aggregates formed with spermidine and its analogs (AP7 or AP8). Additionally, DNA condensates of spermidine analogs were macroscopically different in being more flocculent compared to the compact DNA pellets induced by spermidine. These differences may be related to the nature of cross-linking of the DNA helices within the 
aggregates $(14,29,30)$ and increased DNA mobility resulting in the formation of "less rigid" aggregates by spermidine analogs.

Analysis of cleavage of aggregated Col E1 DNA by $S_{1}$ nuclease. The single strand specific endonuclease $S_{1}$ is widely used to detect sequence-dependent DNA structural perturbations (31). A well characterized palindromic sequence present in negatively supercoiled $\mathrm{Col}_{1} \mathrm{E}_{1}$ DNA makes it an excellent substrate for $S_{1}$ nuclease, with formation of a unit length linear product $(32,33)$. Analyzing the fragmentation pattern of Col $E_{1}$ DNA described here requires consideration of the mechanism of $S_{1}$ nuclease reaction. Previous studies $(31,32,34)$ suggest that under superhelical strain, specific DNA sequences (inverted repeats, AT rich DNA, Z-DNA) fold into a unique conformation (cruciform loops, B-Z DNA junctions) and that $S_{1}$ nuclease introduces a nick in these regions of single-strand character. In a subsequent slower reaction, the enzyme cuts these nicked circles on the complementary DNA strand across from the nick, thus generating linear DNA molecules. Consistent with this mechanism is the strong dependence of $S_{1}$ cleavage on the degree of negative superhelicity of circular DNA (35). In our earlier studies, performed under conditions where DNA was not aggregated, spermidine was shown to inhibit the nicking of supercoiled $\mathrm{Col}_{1} \mathrm{E}_{1}$ DNA by $\mathrm{S}_{1}$ through reduction of the single-stranded nature of the DNA substrate (16). Introduction of single strand breaks into $\mathrm{Col}_{1} \mathrm{E}_{1}$ supercoiled DNA by mung bean nuclease was also curtailed by spermidine (unpublished results).

The influence of aggregation state on cleavage of $C_{0} E_{1}$ DNA by nuclease $S_{1}$ was examined. The assays were performed at a pH close to neutrality to approximate the conditions for other enzymatic reactions studied below. Nuclease $S_{1}$ retains approximately $2 \%$ of its activity at the $\mathrm{pH}$ of 6.8 used here, relative to its optimal pH of $4.5(31) . \mathrm{S}_{1}$ nuclease, in the absence of additional cations in the reaction mixture, produced a series of 8 to 10 DNA fragments ranging in size from $6.6 \mathrm{~kb}$ full length linear to ca. $1.0 \mathrm{~kb}$ (Figure $4 \mathrm{~b}$ ). The generation of DNA fragments smaller than the unit length linear suggests the occurence of infrequent simultaneous cleavage at different sites on $\mathrm{Col}_{1} \mathrm{E}_{1} \mathrm{DNA}$. Low concentrations of spermidine, not sufficient to induce DNA aggregation, progressively reduced the fragmentation process (Figure 4, c \& d). However, elevated amounts of spermidine in the assay led to a complete change in the reaction products. In the presence of $1 \mathrm{mM}$ spermidine, which aggregated DNA substrate (Figure 1), the following differences were noticed: [i] complete suppression of minor DNA bands arising by simultaneous cleavage of a single molecule; [ii] enhanced production of full-length linear molecules; [iii] some supercoiled and nicked DNA remained unreacted, along with the generation of a new linear DNA band of about $3.3 \mathrm{~kb}$ in size. None of the DNA fragments produced in the absence of spermidine corresponded in mobility to this new fragment (compare Figure 4, b \& e). Further increases in spermidine concentration up to $5 \mathrm{mM}$ did not change the electrophoretic pattern of the reaction products, thus strongly suggesting the involvement of DNA aggregation in this phenomenon. Spermidine analogs [AP5 to AP8], added at 5 $\mathrm{mM}$, all induced the formation of $3.3 \mathrm{~kb}$ linear DNA to an equal extent, with the band being less intense and often showing a slightly different mobility in comparison to that generated by spermidine [data not shown].

The Col $E_{1}$ DNA employed as the substrate in the above assays has $10-20 \%$ nicked and relaxed 


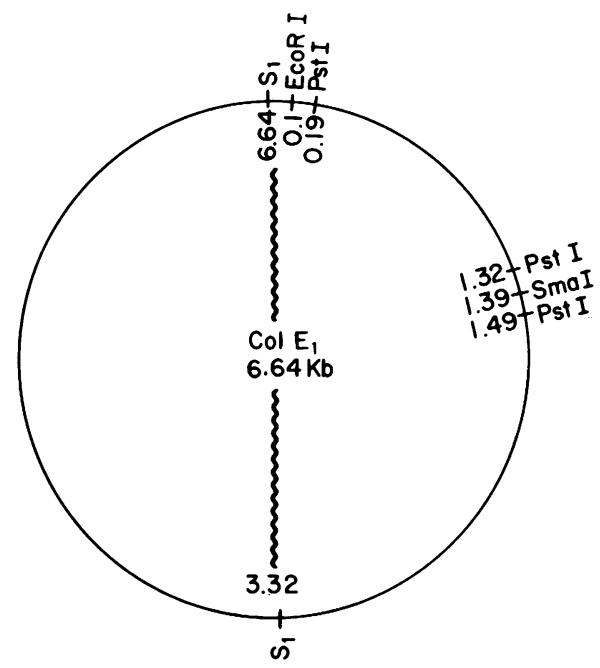

Figure 5: Map of $\mathrm{Col}_{1}$ showing the position of the major $S_{1}$ attack relative to the restriction enzyme sites used in this study. An inverted repeat sequence identified as the major site of $S_{1}$ nuclease attack in Col $E_{1}$ supercoiled DNA is the starting locus of this map. Col E1 DNA sequence (56) was screened to locate the positions of unique restriction sites for EcoRI and Smal enzymes, along with Pstl sites in the right half of the plasmid. The second site that becomes available to $S_{1}$ nuclease in the aggregated $\mathrm{Col} \mathrm{E}_{1}$ supercoiled DNA leading to the cleavage of plasmid in half is postulated based on the results presented in Figure 6.

circles [Figure 4a]. In order to delineate the effect of spermidine, it was of interest to test whether the linear DNA of $3.3 \mathrm{~kb}$ originates from the supercoiled or other topological forms of Col $\mathrm{E}_{1} \mathrm{DNA}$. For this purpose, the plasmid was relaxed using calf thymus topoisomerase I and relaxed DNA was substituted for the original substrate under identical reaction conditions. As expected, relaxed DNA was a poor substrate in $S_{1}$ nuclease reaction; linearization of the nicked and relaxed DNA was slightly stimulated by an aggregating concentration of spermidine without generating any new fragments [Figure 4, g, h \& i].

Other cations were also tested on the fragmentation of supercoiled DNA by $S_{1}$ nuclease. Addition of $100 \mathrm{mM} \mathrm{NaCl}$ to the standard reaction mixture enhanced the production of full-length linear and abolished the formation of smaller DNA fragments without inducing new linear DNA species. Nonaggregating ionic conditions such as $100 \mathrm{mM} \mathrm{NaCl}$ plus $5 \mathrm{mM}$ spermidine did not support the generation of $3.3 \mathrm{~kb}$ DNA. Hexamminecobalt is a trivalent cation that effectively promotes DNA aggregation (29); a faint DNA band of $3.3 \mathrm{~kb}$ was observed in reactions containing $1 \mathrm{mM}$ hexamminecolbalt. Magnesium acetate at $7 \mathrm{mM}$ did not affect the reaction products significantly [data not shown for the above results].

As shown above, cleavage of Col $\mathrm{E}_{1}$ DNA in its aggregated state yielded two linear products viz., a full-length linear of $6.6 \mathrm{~kb}$ and a $3.3 \mathrm{~kb}$ fragment [Figure 4, e \& f]. Simultaneous cleavage at two sites located opposite to each other in the same DNA molecule could result in cutting the plasmid in half, thus producing two comigrating $3.3 \mathrm{~kb}$ fragments. To test this possibility, we analyzed the restriction nuclease 


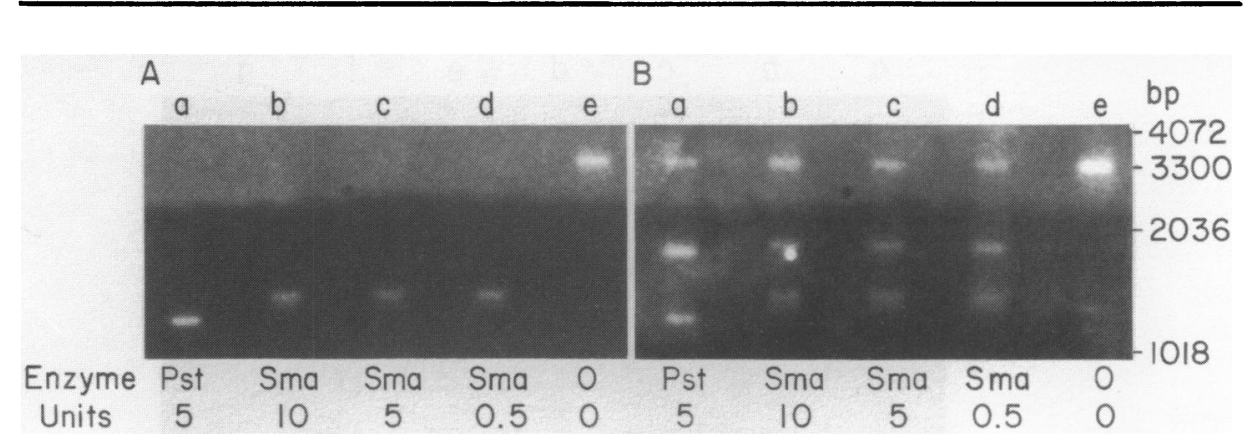

Figure 6: Southern restriction mapping of the $3.3 \mathrm{~kb}$ linear DNA produced by $\mathrm{S}_{1}$ nuclease in response to DNA aggregation. Isolation of a $3.3 \mathrm{~kb} \mathrm{Col} E_{1}$ linear DNA induced by spermidine is described in Experimental Procedures; $6 \mathrm{ng}$ of this purified DNA (shown in lane e; no enzyme) was treated with the restriction enzymes Pstl (a) or varying amounts of Smal (b, c, and d) under optimal ionic conditions. The reaction products were size fractionated in a 1.3\% agarose gel and DNA was transferred to nitrocellulose by standard procedures (22). A restriction fragment located between EcoRI and Smal sites in Col E1 DNA (1.28 kb, see Figure 5) was isolated, nick translated by standard procedures and used to analyze the cleavage pattern of $3.3 \mathrm{~kb}$ DNA. Panel A in the figure depicts the autoradiogram after hybridization with the EcoRI-Smal fragment. Subsequently, the probe was washed off the filter shown in Panel A, and rehybridized with 32P-labeled full-length Col $E_{1}$ DNA, as shown in Panel B. Position of DNA size markers are shown.

pattern of the purified $3.3 \mathrm{~kb}$ DNA by Southern blots using two nick translated DNA probes. Col E1 DNA has unique sites for EcoRI and Smal restriction enzymes (36). The inverted repeat sequence in Col $E_{1}$ DNA, identified as the primary target of $S_{1}$ nuclease is located about 100 base pairs from the EcoRI site (33). Further, Pst1 sites on this plasmid DNA are present in the vicinity of EcoRI and Smal sites as summarized in Figure 5 . We hypothesized that the simultaneous cleavage by $S_{1}$ nuclease to generate two $3.3 \mathrm{~kb}$ pieces might involve its primary target site and a diametrically opposite locus created in response to DNA aggregation. The spatial distribution of the known sites on the Col E1 DNA circle enabled us to predict the size of fragments resulting from the restriction enzyme digestion of the purified $3.3 \mathrm{~kb}$ linear DNA and to design appropriate hybridization probes [Figure 5]. Figure 6 illustrates the autoradiographic patterns of a Southern blot first hybridized with a EcoRI-Smal fragment of Col E1 DNA [panel A] and then reprobed with full-length [32P]Col $E_{1}$ plasmid [panel B]. Restriction reactions were performed with enzymes in excess [up to 1500-fold] over a range of increasing concentration to ensure complete digestion of the 3.3 kb DNA. Consistent with the hypothesis (Figure 5), single bands of 1.1 and $1.4 \mathrm{~kb}$ were hybridized with the labeled EcoRI-Smal fragment in Pstl and Smal digests, respectively [Figure 6, panel A]. Two extra fragments, one of $3.3 \mathrm{~kb}$ and the other of nearly $2 \mathrm{~kb}$ in size appeared in the autoradiogram when the blot was reprobed with complete, nick-translated Col $E_{1}$ DNA [Figure 6, panel B]. The difference in the sizes of the fragments generated in Pstl and Smal digests is consistent with the location of their sites represented in Figure 5.

Influence of spermidine and its analogs on the activities of several enzymes at low and high ionic strength. The spermidine concentration required for compaction of DNA is a function of the 


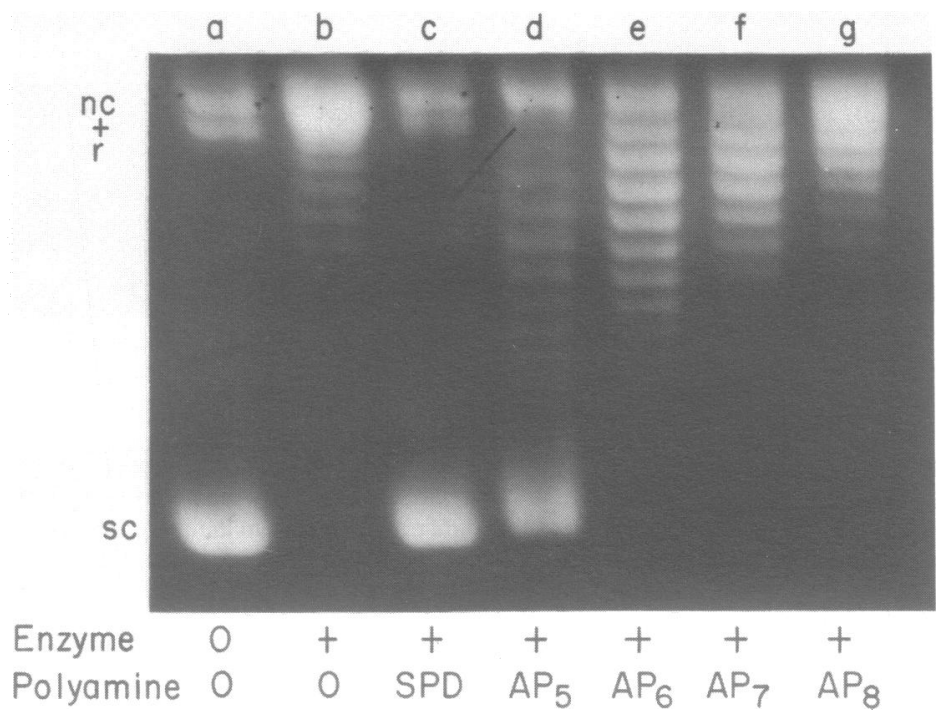

Figure 7: Effect of spermidine and its analogs on the relaxing activity of $E$. coli topoisomerase $I$. Removal of superhelical turns by E. coli topoisomerase I $(35 \mathrm{ng}, 20$ min reaction) was examined at low ionic strength in the presence of spermidine and its analogs (added at $6 \mathrm{mM}$ ). The reaction mixtures contained $20 \mathrm{mM}$ Tris- $\mathrm{HCl}$ (pH 7.5), $5 \%$ glycerol, and $3 \mathrm{mM} \mathrm{MgCl} 2$. DNA aggregation was complete in the reactions $b, c, e$ and increasingly less aggregated in $f$ and $g$, respectively (see text). Supernatants of duplicate reactions after centrifugation were electrophoresed to check the level of DNA aggregation (see Experimental Procedures for details).

concentrations of monovalent and divalent cations $(17,21)$. We adjusted the ionic conditions to examine the influence of spermidine on enzyme reactions using soluble or aggregated DNA as substrates; spermidine and its analogs [AP5 to $\mathrm{AP}_{8}$ ] were tested at equal concentrations in these assays containing negatively supercoiled DNA substrates. The low salt assay conditions used here permitted 100\% DNA aggregation by spermidine, $\mathrm{AP}_{5}$ and $\mathrm{AP}_{6}$ at the concentrations employed and compaction of substrate DNA into a sedimentable form was partial [30 to 45\%] in the case of AP7 and AP8. No DNA aggregation was detected by any of the polyamines under the high salt assay environment.

(i.) E. coli topolsomerase I. Removal of supercoils by E. coli topoisomerase I is strongly curtailed by spermidine, with inhibition being most prominent when the DNA is in the aggregated form (16). Figure 7 presents a comparison of inhibition by spermidine and its analogs at low ionic strength. Spermidine, AP5 and AP6 produced complete aggregation under these conditions, but the two analogs showed progressively less ability than spermidine to inhibit topoisomerase activity [Figure $7, b$ to e]. AP7 and AP8 were only partially aggregating and were not inhibitory under these conditions. However, it is interesting to note that, at $11 \mathrm{mM} \mathrm{AP7}$, which produced $100 \%$ aggregation, inhibition by AP7 was still incomplete relative to spermidine (Figure 8d). At $100 \mathrm{mM} \mathrm{K+}$ and $3 \mathrm{mM} \mathrm{Mg} 2+$ (no aggregation), there was no significant difference in inhibition between spermidine and the four analogs (data not shown). 


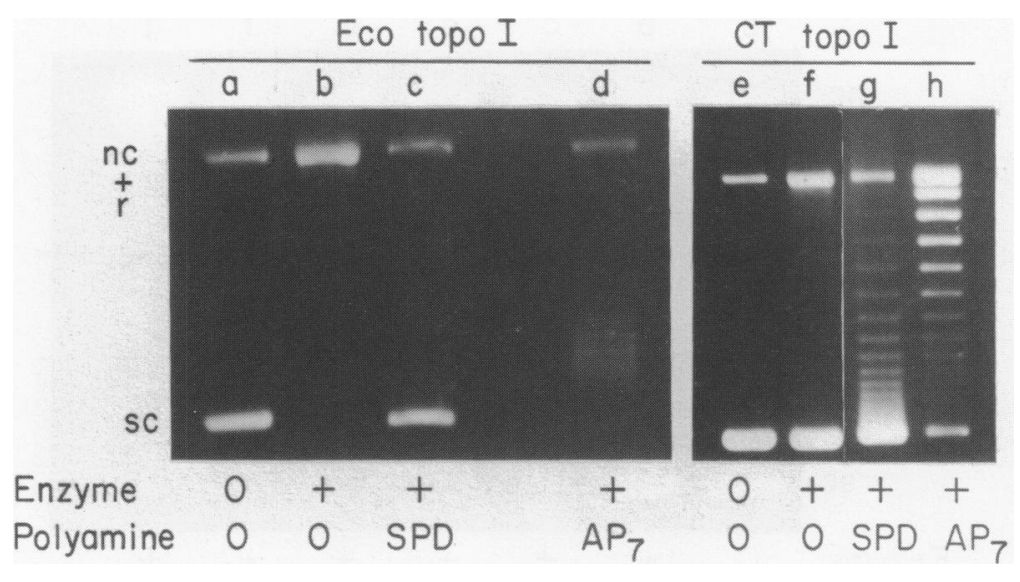

Figure 8: Activity of type 1 topoisomerases on DNA aggregated by spermidine or AP7. The low ionic strength conditions described in Figures 7 and 9 were employed for enzyme assays. DNA substrates were completely aggregated by the addition of $11 \mathrm{mM}$ spermidine or AP7 in the case of $E$. coli topoisomerase I or $8.5 \mathrm{mM}$ with calf thymus type I topoisomerase. Electrophoretic analysis of the duplicate reaction samples containing spermidine or AP7 showed complete DNA aggregation in these experiments.

(ii.) Calf thymus topoisomerase I. Type I topoisomerases from eukaryotic sources are stimulated by spermidine in contrast to the inhibition observed with E. coli type I enzymes (16). Relaxation of DNA by the eukaryotic enzymes is optimal with 160 to $200 \mathrm{mM}$ monovalent cations (37) and spermidine substitutes for monovalent cations in this reaction. Figure 9 demonstrates the influence of spermidine and its analogs on the reaction catalyzed by calf thymus topoisomerase $I$ in the presence of $20 \mathrm{mM} \mathrm{KCl}$. As demonstrated by the disappearance of supercoiled material, the stimulation of the reaction is greater as the chain length of the analog increases. This is true for $\mathrm{AP}_{6}$, where aggregation is complete, as well as AP7 and AP8, which show partial aggregation under these conditions. This was also the case for $8.5 \mathrm{mM}$ spermidine and AP7, (Figure 8, g \& h) conditions that yield 100\% aggregation with both triamines.

(iii.) E. coll DNA gyrase. Aggregation of DNA induced by spermidine is a requirement for the catenation reaction catalyzed by DNA gyrase (17). Introduction of negative superhelical turns by gyrase is also stimulated by low concentrations of spermidine; however, compacted DNA is not an efficient substrate for the supercoiling reaction (reference 38 and our unpublished results). Catenation of relaxed Col $E_{1}$ DNA circles by gyrase was assayed in reactions containing $2 \mathrm{mM} \mathrm{MgCl}_{2}$ and $15 \mathrm{mM} \mathrm{KCl}$ in the presence of $5.5 \mathrm{mM}$ spermidine analogs or spermidine. While spermidine supported an appreciable amount of catenation and essentially no supercoiling, the analogs enhanced formation of both catenanes and supercoiled topoisomers, with AP7 and AP8 being maximally effective. Spermidine analogs stimulated the supercoiling reaction to the same extent as spermidine when DNA was disaggregated [data not shown]. Relaxation of supercoiled Col $E_{1}$ DNA by gyrase, a type II topisomerase, was also 


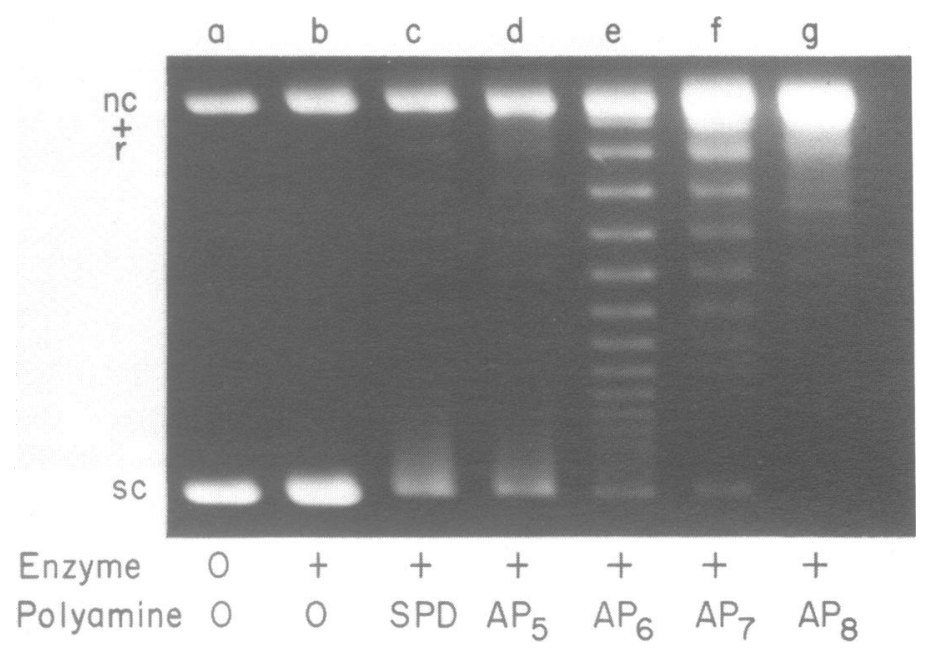

Figure 9: Stimulation of calf thymus type 1 topoisomerase by spermidine and its analogs. Relaxation of $C_{0} E_{1}$ DNA by the enzyme ( 0.4 units, 25 min reaction) was assayed with or without $5.5 \mathrm{mM}$ spermidine and its analogs. The reaction mixtures contained $20 \mathrm{mM}$ Tris- $\mathrm{HCl}(\mathrm{pH} 7.5), 0.5 \mathrm{mM}$ dithiothreitol (DTT), $6 \%$ glycerol and $20 \mathrm{mM} \mathrm{KCl}$. DNA aggregation was incomplete in reactions $f$ and $g$.

inhibited by spermidine-induced DNA aggregation; spermidine analogs were not tested at aggregating concentrations. When DNA was not compacted, the gyrase relaxation reaction was stimulated to a similar extent by spermidine and its analogs [data not shown].

(iv.) EcoRI nuclease. Polyamines like spermidine and spermine have been shown to stimulate the EcoRI reaction and effectively suppress cleavage at degenerate sites $(39,40)$. The influence of spermidine and its analogs on the conversion of supercoiled Col $E_{1}$ DNA to its full-length linear form by EcoRl is depicted in Figure 10. It is clear that aggregation of DNA by spermidine enhances the linearization significantly; the enzyme also appears to nick supercoiled DNA in its compacted form [Figure 10c]. Perhaps related to this observation is the site-specific nicking by EcoRI of supercoiled DNA, saturated with ethidium bromide (41). Production of Col $E_{1}$ linear DNA by the enzyme was greatly enhanced by spermidine analogs relative to spermidine in low salt environment [Figure 10, $d$ to g]. The stimulatory effect of the analogs was similar to that of spermidine in reaction mixtures containing high concentrations of $\mathrm{Mg}^{2}+$ and $\mathrm{Na}+$ ions [Figure $10, \mathrm{~h}$ to $\mathrm{n}$ ].

(v.) Phage lambda integrative recombination. Phage lambda integrates into its host by a single reciprocal recombination between the bacterial chromosome and a circular form of the phage DNA. Int protein, coded by the virus, and integration host factor present in $\mathrm{E}$. coli are the two proteins that mediate recombination between attP and attB sites of the phage and bacterial DNA respectively (42). Phage lambda fails to grow on polyamine-deficient E. coli hosts (43) and spermidine is a strong requirement for the recombination reaction in vitro (18). To explore if the structure of the polyamine is critical in this reaction, we have examined the behavior of spermidine analogs in this system. Spermidine 


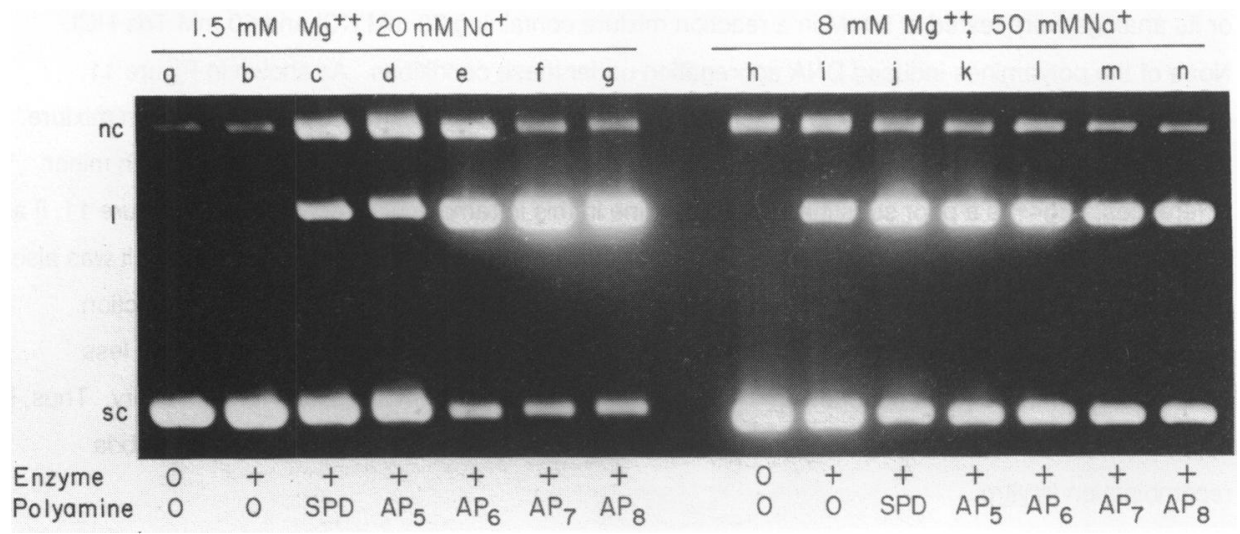

Figure 10: Effect of spermidine or its analogs on the linearization of Col E1 DNA by restriction endonuclease EcoRl. EcoRI ( 0.35 units; 30-min reaction) was assayed in the presence and absence of DNA aggregation. The compositions of the reaction mixtures were $20 \mathrm{mM}$ Tris- $\mathrm{HCl}(\mathrm{pH} 7.5), 1 \mathrm{mM} \mathrm{DTT}$, $1.5 \mathrm{mM} \mathrm{MgCl} 2$ and $20 \mathrm{mM} \mathrm{NaCl}$ in the assay was used to favor DNA aggregation and $50 \mathrm{mM}$ Tris-HCl, $1 \mathrm{mM} \mathrm{DTT}, 8 \mathrm{mM} \mathrm{MgCl} 2$, and $50 \mathrm{mM} \mathrm{NaCl}$ in order to avoid aggregation. The concentrations of spermidine or its analogs were $5.5 \mathrm{mM}$ in both types of reactions. DNA aggregation was complete in the reaction samples $c, d, e$ and partial in $f$ and $g$. Col $E_{1}$ DNA did not aggregate in samples $j$ to $n$. Positions of nicked, linear and supercoiled DNA are indicated.

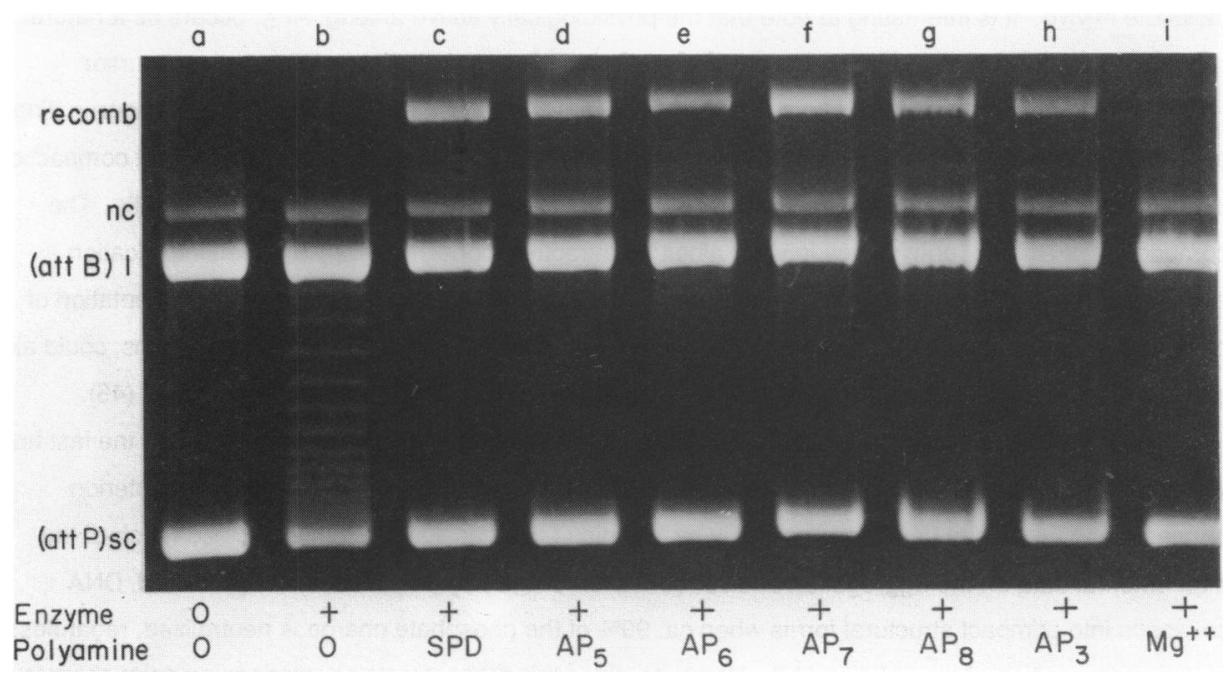

Figure 11: Influence of spermidine and its analogs in supporting phage lambda integrative recombination in vitro. Reaction conditions for the recombination assay have been described in Experimental Procedures. The concentration of polyamines was $5 \mathrm{mM}$ in these reactions. DNA failed to aggregate in any of the samples. $\mathrm{AP}_{3}$ is $\mathrm{N}$-(3-aminopropyl)-1,3-diaminopropane. Effect of $\mathrm{Mg}^{2}+$ ion at 7 $\mathrm{mM}$ was tested for comparison. Positions of supercoiled circles bearing the att P site, linear DNA with the att B site and the recombinant band are marked. 
or its analogs were tested at $5 \mathrm{mM}$ in a reaction mixture containing $70 \mathrm{mM} \mathrm{KCl}$ and $50 \mathrm{mM}$ Tris- $\mathrm{HCl}$. None of the polyamines induced DNA aggregation under these conditions. As shown in Figure 11, production of a recombinant band is evident only when a polyamine was present in the reaction mixture. It is clear that spermidine analogs supported recombination to a similar level as spermidine with minor differences. $\mathrm{Mg}^{2}+$ is a poor substitute for spermidine in this intramolecular recombination [Figure 11, i] as reported earlier (18). Aggregated DNA did not favor efficient recombination. Hexamminecobalt was also tested in the recombination assay. Addition of this cation at 0.5 or $1.0 \mathrm{mM}$ to the standard reaction mixture resulted in the formation of recombinant product in detectable amounts, about 4-6 fold less relative to spermidine [data not shown]. Higher concentrations of the metallic ion were inhibitory. Thus, it appears reasonable to conclude that charge shielding is a major function of polyamines in lambda recombination in vitro.

\section{DISCUSSION:}

Previous studies of the activity of spermidine analogs in polyamine-deficient E. coli strains have provided a frame of reference which may be of use in identifying specific interactions of polyamines that are of physiological interest. A clear biological specificity in supporting growth and macromolecular synthesis was observed; biological activity declined as the spacing between the charged amino groups was increased by addition of methylene groups (8). Thus, an optimal spacing between the nitrogen atoms in the diaminobutane portion of spermidine is an important structural feature in interactions of this molecule in vivo. It is interesting to note that the physiologically active analog, $A P_{5}$, occurs as a natural compensatory polyamine in putrescine-deficient cells, when cadaverine is available as a precursor $(10,44)$. In this paper, we have shown that the effectiveness of these spermidine analogs in aggregating supercoiled DNA correlates with their ability to support cell growth, opening the possibility that compaction of DNA could be a physiologically relevant role of spermidine in prokaryotic and eukaryotic cells. The compaction of DNA by polyamines in vitro, albeit an attractive model, is clearly an oversimplification because of the high ionic strength found in living cells (45). However, intracellular compartmentation of polyamines, together with macromolecular crowding and the presence of DNA-binding proteins, could aid in this process. The functional compartmentation of $\mathrm{Mg}^{2}+$ in cells is of interest in this context (46).

The nature of intramolecular DNA condensation has been a subject of interest during the last few years, since compact DNA structures are a feature common to all living organisms. The counterion condensation theory, as developed primarily by Manning (15), has successfully explained much of the experimental data on the aggregation and condensation of DNA by polyamines. As predicted, DNA collapses into compact structural forms when ca. $90 \%$ of the phosphate charge is neutralized, regardless of ionic composition of the solution (47). However, since this theory treats counterions as point charges with no structural definition, cations of the same charge should produce essentially identical condensed structures. The trivalent spermidine analogs are of interest in this context and have been employed in several physicochemical studies (12-14). Definite structural effects have been observed in DNA condensation, thermal helix-coil transition and $B-Z$ transition $(12,14,48,49)$. Thus, the simple counter ion 
condensation theory does not account for the structural specificity of cations seen in the current study and by others.

The mobility of the polyamines bound to the aggregated complexes is of interest. We previously demonstrated that tumbling of spermidine or spermine molecules bound to a soluble dodecamer DNA duplex is effectively independent of the DNA, but shows a correlation time somewhat longer than that of the free polyamine in solution (50). The proton NMR studies reported here show that spermidine and AP8 in the aggregates are quite mobile (correlation time of $42 \mathrm{nsec}$ ), but very significantly less so than the triamines in solution. The 31P NMR data presented in Figure 3 provide further insight into the interaction of the DNA-phosphate backbone with polyamines. The nearly symmetrical spectrum of calf thymus DNA condensed with spermidine is similar to that of hydrated calf thymus DNA in the solid state (28), suggesting that the ionic cross links do not have a large effect on internal motion of the helices, as was also concluded from fluoresence anisotropy studies (51). DNA aggregates formed by AP7 and AP8 exhibited slightly shamer $31 \mathrm{P}$ and $1 \mathrm{H}$ spectra, as compared with those of DNA compacted by spermidine; this suggests a small increase in the mobility of the spermidine analogs that could have arisen from the looser packing of the helices due to the longer methylene bridges formed by the analogs. Several published results support these conclusions. Schellman \& Parthasarathy (14) interpreted their X-ray diffraction studies to indicate that the intrahelical spacing in DNA collapsed by the homologous series of spermidine analogs increased with the length of the methylene chain. These authors suggested that the arrangement of the DNA strands in these complexes is determined by the structure of the polyamine and not by a balance of long range electrostatic repulsive and attractive forces. Differential aggregation of DNA by AP7 and AP8 (12) and the data suggesting a high mobility of polyamines in condensed DNA (52) are also in agreement with the results presented here. Thus these data are inconsistent with static, crystal-like models of condensed polyamine-DNA complexes.

Supercoiled DNA in the aggregated state is a reasonable model for compacted DNA in the intact cell. The combination of circularity and superhelicity are likely to introduce constraints into the structure of the compacted state and available information in this area is limited (53). The nuclease $S_{1}$ studies described here give some insight into this structure. Aggregation of superhelical Col $E_{1}$ DNA generates a new site of $S_{1}$ cleavage that is 1800 around the plasmid from the major site of attack. In order to account for this behavior, we propose that supercoiled DNA is incorporated into the aggregates in the form of constrained supercoiled rods; folding of the plasmid DNA into these rods may be stabilized through formation of S1-sensitive cruciforms on opposite sides of the circular molecules. Consistent with this proposal is the observation that spermidine-aggregated plasmid DNA contained a large proportion of "folded fiber rods" rather than toroidal forms (54). The mechanism of double cleavage of a single plasmid molecule by nuclease $S_{1}$ is of interest. This could be due to simultaneous attack at both sites or, alternatively, it is possible that the superhelical density is retained for an extended period of time due to structural constraints within the aggregate, which in turn would increase the probability of attack at the second site. In the context of the latter model, it is interesting to note that the cleavage of Col E1 DNA into two fragments is much less efficient in the less rigid aggregates formed by the spermidine analogs. 
In considering the accessibility of aggregated DNA to enzymatic action, several aspects should be considered. Supercoiled DNA in a compacted lattice might present or occlude preferential binding sites, depending on the structure and rigidity of the complex. DNA substrates might exist in an altered conformation when compacted, as revealed in the $S_{1}$ nuclease studies discussed above. DNA aggregates are dynamic structures, capable of dispersing rapidly and exchanging material with neighboring aggregates (17); although the mechanism and the conditions that modulate this exchange process are not completely defined, the possibility of free DNA access to enzyme reactions during the rearrangement should be considered. Other possible considerations in the interaction of enzymes with condensed DNA are the possible penetration of the enzyme into the gel phase, the influence of locally elevated DNA concentration and constraints on DNA mobility introduced by the structure of the lattice.

In the enzyme reaction mixtures at low ionic strength, it is important to emphasize that complete aggregation of the substrate DNA was achieved by spermidine, AP5, AP6 and high concentrations of AP7. It was only under these conditions that structural specificity was observed when spermidine and its analogs were compared. At moderate ionic strength, where DNA was not aggregated, this structural specificity was lost and the analogs behaved in a manner indistinguishable from spermidine; under these conditions, the effects on enzyme activities are probably related to simple charge neutralization.

The relaxation of supercoiled DNA, in either the soluble (16) or the aggregated (this paper) state, by calf thymus topoisomerase I is stimulated by spermidine. Specificity for the spermidine analogs was observed under conditions of complete aggregation; the longer chain analogs activated more strongly than spermidine. Since no structural specificity was observed in the absence of aggregation, it seems likely that this arises from differences in the structure of the compacted DNAs. Removal of supercoils must require mobility of the molecule during nicking and resealing of the DNA strands by the topoisomerase. Thus, the greater internal mobility of the DNA in aggregates formed with the spermidine analogs could very well allow for a higher rate of topoisomerization and hence the observed specificity.

Interpretation of the influence of the triamines on the activity of E. coli topoisomerase I is more complex. Besides the effects of aggregation on the conformational mobility of the DNA, this enzyme requires single stranded regions in supercoiled DNA as sites of action (55). Spermidine (and its analogs) inhibits this enzyme by decreasing the single stranded nature of the substrate (16). This inhibition occurs via modification of the electrostatic potential of the DNA and therefore does not show structural specificity for the triamines. Thus, under conditions of aggregation, spermidine inhibits this enzyme in two ways: by restricting the mobility of the DNA (as above for eukaryotic topoisomerase I) and by decreasing its degree of single strandedness (except specifically at the poles of the compacted, supercoiled rods). The spermidine analogs are less inhibitory because of the greater fluidity of the DNA in the aggregates.

Spermidine can modify the biological activity of DNA in at least two ways. Neutralization of the electrostatic potential of DNA can have many effects, including reducing the single stranded nature of negatively supercoiled molecules. This latter effect inhibits the activity of enzymes that depend on single stranded regions for catalytic action (16). Charge neutralization should depend on the valence of the cation, but would not be expected to be influenced highly by its structure. This prediction was born out in 
the current study; in the absence of DNA aggregation, the influence of the spermidine analogs on the activity of the various enzymes studied was identical to that of spermidine. A similar result was obtained for cell-free DNA replication of phage $\Phi \times 174$ DNA (11). As shown in this paper, spermidine also can modulate the structure of compacted DNA structures, with concomitant alteration of the activity of enzymes using this DNA as substrate. Both the structure of the condensed DNA and its activity as substrate depends on the structure of the triamine in a way reminiscent of the biological activity of these compounds $(8,10)$. Thus, it is tempting to suggest that a major role of polyamines in the intact cell is to participate in the formation of the compact DNA structures common to all living organisms.

Acknowledgements: We thank Dr. Robert Low, Washington University, and Dr. Martin Gellert, National Institutes of Health, for gift samples of topoisomerases. We are grateful to Dr. Howard Nash for his interest and for providing facilities and resources of perform the lambda recombination assays. Thanks are also due to Dr. Terho Eloranta, Kuopio University, Finland, for initiating experiments with spermidine analogs and DNA gyrase in this laboratory. This work was supported by a National Science Foundation research grant (PCM8301985) and instrumentation grants from the Murdock Foundation, the National Science Foundation (PCM8018053) and the National Institutes of Health (GM28764-01S1).

*Present address: Department of Chemistry, University of California, Berkeley, CA 94720, USA

$\S$ To whom correspondence should be addressed

\section{REFERENCES:}

1. Cohen, S. S. (1971) Introduction to the Polyamines, Benjamin Hill, Englewood Cliffs, N.J.

2. Tabor, C. W., \& Tabor, H. (1976) Annu. Rev. Biochem. 45, 285-306

3. Morris, D. R. \& Marton, L. J. (1981) Polyamines in Biology and Medicine, Marcel Dekker, New York.

4. Heby, O., \& Janne, J. (1981) In Morris, D. R., \& Marton, L. J. (eds), Polyamines in Biology and Medicine, Marcel Dekker, New York, pp. 243-310.

5. Tabor, C. W., \& Tabor, H. (1984) Annu. Rev. Biochem. 53, 749-790.

6. Marton, L. J., \& Morris, D. R. (1986) In McCann, P. P., Pegg, A. E., and Sjoerdsma, A. (eds) Inhibition of Polyamine Biosynthesis: Biological Significance and Basis for New Therapies, Academic Press, Inc., New York, in press.

7. Bloomfield, V. A., \& Wilson, R. W. (1981) In Morris, D. R., and Marton, L. J., (eds), Polyamines in Biology and Medicine, Marcel Dekker, New York, pp. 183-206.

8. Jorstad, C. M., Harada, J., \& Morris, D. R. (1980) J. Bacteriol. 141, 456-463.

9. Geiger, L. E., \& Morris, D. R. (1980) J. Bacteriol. 141, 1192-1198.

10. Porter, C. W., \& Bergeron, R. J. (1983) Science 219, 1083-1085.

11. Geiger, L. E., \& Morris, D. R. (1980) Biochim. Biophys. Acta. 609, 264-271.

12. Allison, S. A., Herr, J. C., \& Shurr, J. M. (1981) Biopolymers 20, 469-488.

13. Thomas, T. J., \& Bloomfield, V. A. (1984) Biopolymers 23, 1295-1306.

14. Schellman, J. A., \& Parthasarathy, N. (1984) J. Mol. Biol. 175, 313-329.

15. Manning, G. S. (1978) Quart. Rev. Biophys. 11, 179-246.

16. Srivenugopal, K. S., \& Morris, D. R. (1985) Biochemistry 24, 4766-4771.

17. Krasnow, M. A., \& Cozarelli, N. R. (1982) J. Biol. Chem. 257, 2687-2693.

18. Nash, H. A., \& Robertson, C. A. (1981) J. Biol. Chem. 256, 9246-9253.

19. Maniatis, T., Fritsch, E. F., \& Sambrook, J. (1982) Molecular Cloning, CSH Laboratory Publication, Cold Spring Harbor, N.Y.

20. Thomas, P. S. (1980) Proc. Natt. Acad. Sci. USA 77, 5201-5205. 
21. Osland, A., \& Kleppe, K. (1977) Nucleic Acids Res. 4, 685-695.

22. Gosule, L. C. \& Schellman, J. A. (1978) J. Mol. Biol. 121, 311-326.

23. Hoopes, B. C., \& McClure, W. (1981) Nucleic Acids Res. 9, 5493-5504.

24. Marx, K. A., \& Reynolds, T. C. (1983) Biochim. Biophys. Acta 741, 279-287.

25. Bloembergen, N., Purcell, E., \& Pound, R. V. (1948) Phys.Rev. 73, 679.

26. Hogan, M., \& Jardetzky, O. (1980) Biochemistry 19, 3460-3468.

27. Fujiwara, T., \& Shindo, H. (1985) Biochemistry 24, 896-902.

28. Mai, M. L., Wemmer, D. E., \& Jardetzky, O. (1983) J. Am. Chem. Soc. 105, 7149-7152.

29. Widom J., \& Baldwin, R. L. (1980) J. Mol. Biol. 144, 431-453.

30. Suwalsky, M., Traub, W., Shmueli, U., \& Subirana, J. (1969) J. Mol. Biol. 42, 363-373.

31. Shishido, K., \& Ando. T. (1982) In Linn, S. M., \& Roberts, R. J. (eds), Nucleases, Cold Spring Harbor Laboratory, N.Y., pp. 155-185

32. Lilley, D. M. J. (1980) Proc. Natl. Acad. Sci. USA 77, 6468-6472.

33. Lilley, D. M. J. (1984) Biochem. Soc. Trans. 12, 127-140.

34. Singleton, C. K., \& Wells, R. D. (1982) J. Biol. Chem. 257, 6292-6295.

35. Shishido, K. (1980) FEBS Lett. 111, 333-336.

36. Dougan, G., Saul, M., Warren, G., \& Sheratt, D. (1978) Molec. Gen. Genet. 158, 325-327.

37. Liu, L. F. (1984) CRC Crit. Rev. Biochem. 15, 1-23.

38. Gellert, M., Mizuuchi, K., O'Dea, M. H., \& Nash, H. (1976) Proc. Natl. Acad. Sci. USA 73, 3872-3876.

39. Pingoud, A., Urbanke, C., Alves, J., Ehbrecht, H. J., Zabeau, M., \& Gualerzi, C. (1984) Biochemistry 23, 5697-5703.

40. Pingoud. A. (1985) Eur. J. Biochem. 147, 105-109.

41. Goppelt, M., Langowski, J., Pingoud, A., Haupt, W., Urbanke, C., Mayer, H., \& Maass, G. (1981) Nucleic Acids Res. 9, 6115-6126.

42. Weisberg, R. A., \& Landy, A. (1983) In Hendrix, R. W., Roberts, J. W., Stahl, F. W., \& Weisberg, R. A (eds), Lambda II, Cold Spring Harbor Laboratory Publication, Cold Spring Harbor, N. Y., pp. 211 242.

43. Hafner, E. W., Tabor, C. W., \& Tabor, H. (1979) J. Biol. Chem. 254, 12419-12426.

44. Igarashi, K., Kashiwagi, K., Hamasaki, H., Miura, A., Kakegawa, T., Hirose, S., \& Matsuzaki, S. (1986) J. Bacteriol. 166, 128-134.

45. Rubin, R. L. (1977) J. Bacteriol. 129, 916-925.

46. Gunther, T. (1986) Magnesium 5, 53-59.

47. Wilson, R. W., \& Bloomfield, V. A. (1979) Biochemistry 18, 2192-2196.

48. Thomas, T. J., \& Bloomfield, V. A. (1985) Biopolymers 24, 725-729.

49. Burton, D. R., Forsen, S., \& Reimarsson, P. (1981) Nucleic Acids Res. 9, 1219-1228.

50. Wemmer, D. E., Srivenugopal, K. S. Reid, B. R., \& Morris, D. R. (1985) J. Mol. Biol. 185, 457-459.

51. Ashikawa, I., Furuno, T., Kinosita, K., Ikegami, A., Takahashi, H., \& Akutsu, H. (1984) J. Biol. Chem. 259, 8338-8344.

52. Porscke, D. (1984) Biochemistry 23, 4821-4823.

53. Grosberg, A. Y., \& Zhestkov (1985) J. Biomol. Struct. Dyn. 3, 515-520.

54. Eickbush, T. H., \& Moudrianakis, E. N., (1978) Cell 13, 295-306.

55. Srivenugopal, K. S. \& Morris, D. R. (1986) Biochem. Biophys. Res. Commun. 137, 795-800.

56. Chan, P. T. Ohmori, H., Tomizawa, J., \& Lebowitz, J. (1985) J. Biol. Chem. 260, 8925-8935. 